\title{
DETERMINANTS DE L'EMANCIPACIÓ
}

\author{
Anna García Masiá ${ }^{1}$ i Josep Roca Cladera \\ Centre de Política de Sòl i Valoracions \\ Universitat Politècnica de Catalunya
}

Remisión Artículo: 25-9-2007

Palabras Clave: Joventut, emancipació, habitatge social, formació de la llar

Resumen: El present article té per objecte exposar els principals factors determinants en el procés d'emancipació de la joventut, a partir de l'explotació de les dades dels censos i padrons i de les obtingudes a partir d'una enquesta específica, per tal d'avançar en el coneixement d'aquest procés i, alhora, afavorir i orientar la política social i d'habitatge en la matèria. Partint de la premissa de la rehabilitació i conversió d'usos i espais a partir de la flexibilització del mercat residencial i els règims de tinença, afavorint el valor d'ús per sobre el valor de canvi; tot afavorint la resocialització cap a un valor social de l'habitatge.

\section{INTRODUCCIÓ}

En un moment de creixement econòmic, expansionista, en què la desregulació del mercat de sòl ha facilitat la descalificació i recalificació d'aquest segons convingués i fomentant pràctiques especulatives. Quan la construcció ha protagonitzat el creixement del Producte Interior Brut (PIB), representant fins el 17,7\% el 2003 i acaparant l'11,9\% de la població activa, amb l'edificació residencial com la principal font d'activitat (generant el 33\% de la producció total el $2003)^{2}$ i quan la llei de l'oferta i la demanda no ha complert la seva màxima, ans al contrari, quanta més oferta ha hagut més han incrementat els preus. Paral-lelament, els bancs i les caixes han enginyat tot tipus d'ofertes per pal-liar, que lluny de solucionar, l'elevat increment del preu de l'habitatge que en els darrers anys s'ha triplicat (entre 1991 i 2005 els preus dels habitatges de la RMB han incrementat en un $195 \%{ }^{3}$ ), i la repercussió d'aquest en l'economia domèstica; amb tipus d'interès variables que es situen a mínims històrics (fins el 3,28\% el 2005) i períodes de retorn del préstec cada cop més llargs (creant hipoteques de fins a 50 anys).

L'article data un moment de canvi, en què els tipus d'interès han començat a incrementar, quan la manca d'habitatges protegits construïts els darrers anys comença a repercutir en l'estabilitat de sectors de població cada cop amb més recursos. Quan els moviments socials que s'han creat i mobilitzat al voltant de l'accés a l'habitatge i en defensa d'aquest dret constitucional han repercutit en tots els àmbits, amb un fort poder mediàtic i un inici de consciència política i social sobre la problemàtica. Inaugurada la nova llei estatal de sòl ${ }^{4}$ i a vigílies d'aprovar-se el projecte de llei pel dret a l'habitatge, que tenen per objecte fomentar la transparència i la participació ciutadana, així com el desenvolupament urbà sostenible ${ }^{5}$ i garantir la creació d'un parc públic

\footnotetext{
1 Persona de contacto Anna Garcia Masiá, correu:annagm7@yahoo.es

${ }^{2}$ El sector de la construcción aportó un 17,7\% al PIB en 2003. El Mundo. Economía. 30 de Marzo de 2004

${ }^{3}$ Elaboració pròpia a partir de les dades del Ministerio de la Vivienda.

4 La Llei 8/2007, de 28 de maig, de sòl. Vegi's referència Ángela de la Cruz Mera (2007): La Llei 8/2007, de sòl: principals novetats. L'estatut de la propietat urbana. Jornada tècnica La Llei estatal de sòl: nou marc jurídic per a l'urbanisme municipal. Oficina Tècnica de Cooperació de la Diputació de Barcelona.

${ }^{5}$ La Llei 8/2007 de sòl fa un canvi de les situacions bàsiques de sòl, sòl rural i sòl urbanitzat; tot eliminant l'urbanitzable.
} 
d'habitatges $^{6}$, tot rescatant les plusvàlues urbanístiques en favor de la comunitat i adreçat, expressament als patrimonis públics de sòl ${ }^{7}$. Moment en què aquestes i altres polítiques socials i d'habitatge es posen a prova, elles mateixes i la voluntat d'aquells/es que les porten a terme.

Aquestes situacions econòmiques i polítiques del mercat residencial condicionen l'accessibilitat a l'habitatge de les persones joves en edat d'emancipar-se. Comprendre la forma de vida i cohabitació de les mateixes, les característiques de llurs habitatges actuals i del que desitjarien així com els motius que han interferit en llur procés d'emancipació, bé facilitant-lo bé causantne dificultats, permeten una millor actuació de l'administració competent, que, aprofitant la nova legislació en la matèria podrà aportar solucions viables i desitjables al públic al qual van adreçades. Per a la classificació i categorització de l'emancipació s'utilitzen les dades obtingudes d'una enquesta telefònica ${ }^{8}$ realitzada el mes d'abril de 2007 a 410 joves del Maresme d'entre 15 i 34 anys, 315 dels/les quals ja s'han emancipat i 95 encara no ho han fet però manifesten la voluntat de fer-ho en els propers dos anys. Per tant, la informació no només fa referència a la situació i perspectiva de futur de la mostra emancipada, també de la demanda potencial, oferint la possibilitat d'actuar a les administracions competents per resoldre la problemàtica en un futur.

Per tant, el text s'estructura en els següents apartats:

- Joventut i emancipació (característiques de la joventut emancipada vs no emancipada)

- Llar i habitatge jove

- Determinants del procés d'emancipació

- Conclusions i propostes

\section{JOVENTUT I EMANCIPACIÓ}

Per comprendre el procés d'emancipació i les dificultats que l'envolten cal entendre, d'una banda, en què consisteix la joventut i l'emancipació. Diccionari ${ }^{9}$ en mà, joventut és el temps de la vida entre la infantesa i l'edat madura. Període d'existència d'una cosa que està en ple desenvolupament; i emancipar-se (emancipar) és alliberar (algú) de la pàtria potestat, d'una tutela, de la servitud. Alliberar de qualsevol mena de dependència. Per tant, es tracta del pas cap a la independència de la llar d'origen i la llibertat de la vida adulta. Ara bé, aquest procés no respon únicament a paràmetres demogràfics, requereix una estabilitat econòmica, normalment dependent del mercat de treball, i personal, car es tracta de la formació d'una nova Ilar; però, a més, actualment la formació d'una nova llar implica un altre habitatge, per tant, està lligada al mercat de l'habitatge.

El procés d'emancipació de la llar d'origen es produeix en l'etapa de la joventut, que comprèn uns límits poc clars, car, quan es tracta de l'emancipació i, en dependència de tots els factors que el condicionen per llur acompliment, l'edat incrementa fins la trentena. Donades les actuals dificultats i el retard que s'ha produït en els darrers anys en l'edat mitjana a l'emancipació, en

\footnotetext{
${ }^{6}$ El projecte de Llei pel dret a l'habitatge estableix l'objectiu específic d'aconseguir un parc mínim d'habitatges destinats a polítiques socials del 15\% a Catalunya, en un horitzó de 20 anys, amb l'establiment d'un fons de suport financer per part del Govern de la Generalitat per als municipis que presentin majors dificultats per aconseguir-ho.

Article $16.1, b)$ de la Llei $8 / 2007$. En general del $5 \%$ al $15 \%$, i, amb caràcter excepcional, per a les actuacions especialment lucratives, fins el $20 \%$.

${ }^{8}$ L'enquesta es realitza a la comarca del Maresme, com a mostra de comarca de la Regió Metropolitana de Barcelona que ha experimentat un creixement molt elevat en els darrers anys (és la tercera comarca que més ha incrementat la població total i jove entre 1986 i 2006, amb un 52\% i un 43\% respectivament) com a conseqüència, en gran part, del procés descentralitzador de les grans ciutats cap a la perifèria i, per tant, com a receptora d'aquest.

Per tal d'analitzar la realitat del procés d'emancipació amb la màxima fidelitat, s'han establert quotes de representació per municipi (i no per sexe ni edat), amb un error mostral del $5 \%$.

Gran Diccionari de la Llengua Catalana (1999). Enciclopèdia Catalana.
} 
aquest cas s'ha considerat dels 15 als 34 anys, establint dos grups d'edat en funció de l'estabilitat $i$ consolidació del procés d'emancipació ${ }^{10}$ : el primer grup en edat de primera emancipació (de 15 a 24 anys) i el segon, en edat d'emancipació estable (de 25 a 34 anys).

En la classificació i categorització de la joventut el primer que cal tenir en compte és la divergència entre les variables sociodemogràfiques. Donat que no s'ha forçat la representació per sexe ni edat, aquestes variables no responen a una distribució equitativa, doncs la població emancipada és majoritàriament de més de 24 anys, per tant, les enquestes segueixen aquesta mateixa distribució, amb major proporció d'enquestes en edats inferiors als 25 anys en el cas dels no emancipats i superiors en el cas dels emancipats

La primera mostra que posa de manifest el retard en l'edat d'emancipació és, d'una banda, la reduïda taxa d'emancipació en els grups en edat de primera emancipació (8\%), i de l'altra, la presència d'una quarta part de la mostra de joves en edat d'emancipació estable que no s'ha emancipat (el $25 \%$, dels quals un $8 \%$ tenen 30 anys o més). Igualment, es produeix de forma més tardana en els homes que en les dones, que s'emancipen una mitjana de dos anys abans que els homes, fet que també corroboren les dades de l'enquesta. Ara bé, malgrat l'edat actual de les persones joves emancipades, l'edat que tenien en el moment en què ho van fer mostra una major diversitat amb edats inferiors a l'actual. Adquireixen especial rellevància els dos grups quinquennals intermitjos, que engloben la pràctica totalitat de la mostra emancipada (el $86 \%$ ), amb un $9,5 \%$ de la mostra que es va emancipar amb menys de 20 anys i un 4,4\% que ho va fer passada la trentena, que contrasta amb el $8 \%$ de la mostra no emancipada amb aquesta edat; fet que posa de manifest el retard en el procés d'emancipació, especialment en els darrers anys.

Per tant, l'edat serà un element determinant en tot l'anàlisi, tant pel que fa als aspectes objectius com pel que fa als subjectius, si bé en el cas de la mostra emancipada és més determinant l'edat que tenia en el moment en què va constituir la seva pròpia llar que en el moment present.

\section{CARACTERÍSTIQUES DE LA JOVENTUT EMANCIPADA VS. NO EMANCIPADA ${ }^{11}$}

Les principals característiques que, a més, divergeixen entre la mostra emancipada i la no emancipada es poden dividir en tres grups: educatiu, laboral i econòmic; que alhora es divideixen entre la situació actual i la del moment d'emancipació d'ambdues mostres. A més, la inclusió de la situació que espera tenir la mostra no emancipada en el moment en què ho faci mostra la percepció que té del procés d'emancipació i les expectatives de futur.

A grans trets, la mostra emancipada des del moment en què es va emancipar fins al present ha millorat la seva situació, tant pel que fa al nivell d'estudis com pel que fa a la situació laboral, en estabilitat, categoria socioprofessional i retribució econòmica; però la quota mensual de lloguer o hipoteca ha incrementat en major proporció del que ho ha fet el nivell d'ingressos. El fet que, malgrat aquest increment de la quota mensual per al pagament de l'habitatge, per sobre de l'increment del nivell d'ingressos, no només no incrementi l'esforç econòmic mensual per assumir el cost de l'habitatge, sinó que es redueix, es deu al la reducció del tipus d'interès dels darrers anys.

\footnotetext{
${ }^{10}$ S'han establert dos grups d'edat en funció de l'etapa i consolidació del procés d'emancipació: el primer, en edat de primera emancipació (15-24 anys) que, per llur condició socioeconòmica, laboral,... i per llur edat es troba en una emancipació menys estable i precària ... i el segon, en edat d'emancipació estable (25-34 anys), amb els estudis normalment acabats, es considera que les persones es troben en un altre moment del cicle vital, amb una major estabilitat, econòmica, laboral, personal,... que els porta a consolidar una llar i, sovint, a formar família.

${ }^{11}$ Vegi's annex, quadre 1
} 
Ara bé, a diferència de la mostra emancipada, la que no ho està té una situació més precària pel que fa al món laboral, una taxa d'ocupació més baixa, més precària, amb menors ingressos i de categories inferiors a llurs coetanis emancipats, amb un nivell d'instrucció més baix, però l'expectativa de millora per al moment en què s'emancipin és molt superior a l'actual i a la que té i tenia la mostra emancipada. A més, donen més importància al nivell d'estudis que la mostra que ja s'ha emancipat. Mentre l'expectativa de millora de llur situació és molt optimista, inclús per sobre de la realitat de llurs coetanis emancipats, la percepció que tenen del procés d'emancipació és més pessimista que la d'aquells ${ }^{12}$, amb un cost de l'habitatge esperat més elevat, consideren que el cost mensual de l'habitatge és un $27 \%$ superior.

Per tant, el procés d'emancipació, que en un principi requereix d'un esforç econòmic i personal elevat, amb el temps es consolida, no només en termes econòmics, també pel que fa a la percepció del mateix. Ara bé, això és més cert en el cas del grup de més edat, car, la situació que es dóna en el moment de l'emancipació és menys complexa, doncs, té un major nivell d'ingressos i, per tant pot córrer un major risc (destina una mitjana del $40 \%$ dels ingressos de la llar per al pagament de l'habitatge) reduint-se en el moment present (34\%). Però en el cas de la mostra emancipada més jove (de menys de 25 anys), si bé en el moment de l'emancipació fa un menor esforç econòmic (del 37\% dels ingressos de la llar per al pagament de l'habitatge), en el moment present no només incrementa el percentatge d'ingressos per al pagament de I'habitatge (39,5\%), sinó que, a més, ho fa per sobre del grup de més edat, que té un nivell d'ingressos superiors. Per tant, com més jove és la persona emancipada major és el risc i l'esforç econòmic per al pagament de l'habitatge, superant els llindars màxims assequibles, establerts al voltant del $30 \%$. Que, a més, es situarà en una situació de major risc en actualitzar-se les hipoteques amb el recent i continuat increment del tipus d'interès.

\section{LLAR I HABITATGE JOVE}

El procés d'emancipació segueix un patró tradicional on, l'emancipació, en la majoria dels casos, equival a la formació d'una nova llar nuclear. Per tant, no és d'estranyar que la major part de les llars joves estiguin formades per parelles i/o matrimonis. Ara bé, per tal d'apreciar les diferències entre la joventut en edat de primera emancipació i la d'emancipació estable s'han utilitzat les dades corresponents a l'edat que tenien en el moment de l'emancipació (i no les de l'edat actual), car el grup de menys edat era poc significatiu i la situació en molts casos ha canviat.

\section{Taula 1 Tipologia de les Ilars joves per grups d'edat en el moment de l'emancipació}

\begin{tabular}{lccc|c} 
& Sol/a & Parella & Amics & Total \\
\hline Edat de primera emancipació & 23 & 124 & 14 & 161 \\
(15-24 anys) & 14,29 & 77,02 & 8,70 & 51,11 \\
\hline Edat d'emancipació estable & 15 & 131 & 8 & 154 \\
(25-34 anys) & 9,74 & 85,06 & 5,19 & 48,89 \\
\hline \multirow{2}{*}{ Total } & 38 & 255 & 22 & 315 \\
& 12,06 & 80,95 & 6,98 & 100,00 \\
\hline
\end{tabular}

Font: dades provinents de l'enquesta. Elaboració pròpia

Per tant, el model estructural de les llars joves és bàsicament de llars nuclears simples (81\%) formades per la persona enquestada i llur parella (amb i/o sense fills), amb un pes relatiu de les llars unipersonals (12\%) i les sense nucli (7\%). Ara bé, distingint la tipologia per grups d'edat, es comprova com en edats més joves la diversitat de formes de cohabitació és superior, amb un major percentatge de llars sense nucli formades per dues persones o més $(8,7 \%)$ i amb una major proporció de llars unipersonals; mentre les llars joves de més edat redueixen la proporció d'aquestes en favor de les llars nuclears simples (85\%).

\footnotetext{
${ }^{12}$ amb una valoració 1,45 punts per sobre la valoració de l'1 al 9 del grau de dificultat del procés d'emancipació
} 
Taula 2 règim de tinença dels habitatges joves per grups d'edat en el moment de l'emancipació

\begin{tabular}{lccc|c} 
& Propietat & Lloguer & Cedit & Total \\
\hline Edat de primera emancipació & 113 & 40 & 9 & 162 \\
(15-24 anys) & 69,75 & 24,69 & 5,56 & 51,43 \\
\hline Edat d'emancipació estable & 109 & 35 & 9 & 153 \\
(25-34 anys) & 71,24 & 22,88 & 5,88 & 48,57 \\
\hline \multirow{2}{*}{ Total } & 222 & 75 & 18 & 315 \\
& 70,48 & 23,81 & 5,71 & 100,00 \\
\hline
\end{tabular}

Font: dades provinents de l'enquesta. Elaboració pròpia

El segon factor explicatiu de la tipologia i estructura de la llar és el règim de tinença. Amb una major proporció d'habitatges de lloguer que els del conjunt del Maresme (tant sols el 13,7\% dels habitatges del Maresme són de lloguer ${ }^{13}$ ), per tant, les llars joves resideixen en major proporció que les adultes en habitatges de lloguer $(23,8 \%)$. I, igualment, les més joves tenen una major proporció d'habitatges de lloguer $(24,7 \%)$ que les d'emancipació estable $(22,88 \%)$.

Per tant, les llars més joves, en trobar-se en un moment del procés més precari, sovint subjecte a situacions i processos canviants, formen llars més variades amb estructures i tipologies menys tradicionals. El qual es correspon amb una major proporció d'habitatges de lloguer que de propietat, doncs la facilitat per canviar d'habitatge és superior a la del règim de propietat (econòmicament, fiscalment, per tipologia, localització, característiques,...), tornant-se per tant més flexibles. Mentre el grup de més edat, que ja inicia una emancipació domiciliar més estable, sovint lligada al cicle vital i la formació de la llar familiar, resideix en major proporció en llars nuclears simples i en habitatges de propietat; tot i que la resta de tipologies de llars i de règims de propietat hi són presents en major proporció que a les llars adultes.

Si bé les divergències entre les característiques de les llars segons l'edat no atenyien al règim de tinença, les característiques dels habitatges responen a ambdues variables.

Figura 1 Superfície dels habitatges joves segons règim de tinença i grup d'edat en el moment de l'emancipació

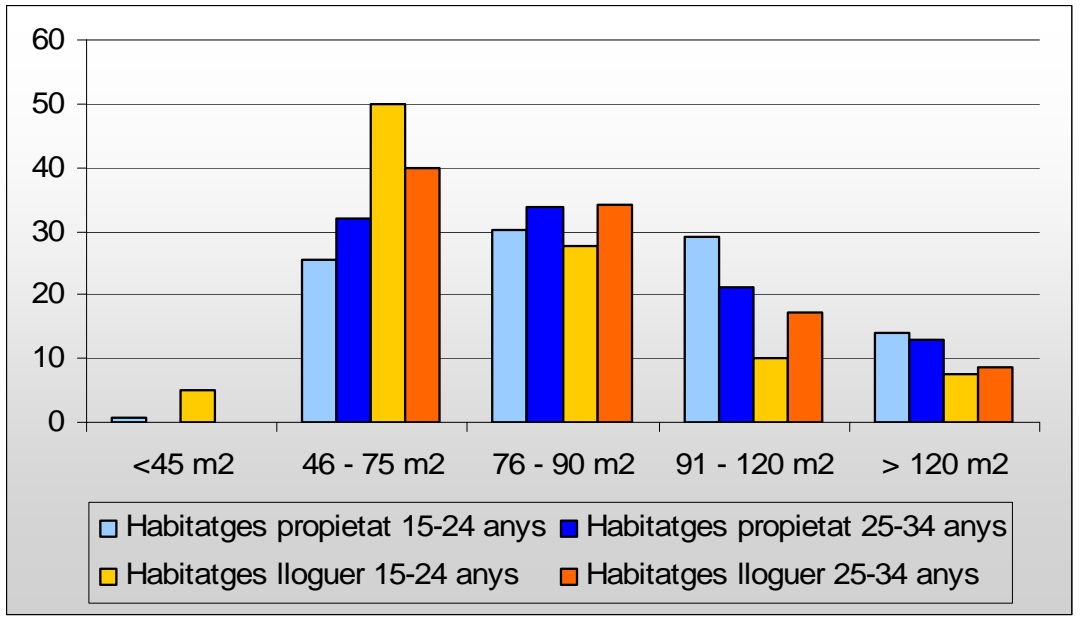

Font: dades provinents de l'enquesta. Elaboració pròpia

\footnotetext{
${ }^{13}$ Dades del cens de 2001. El 81,47\% dels habitatges del Maresme són de propietat, el 13,7\% de lloguer i el 4,83\% cedits. Mentre a la RMB incrementa la proporció d'habitatges de lloguer (un 17,81\%), en detriment dels de propietat (el $78,55 \%)$ i els cedits $(3,65 \%)$.
} 
La primera qüestió diferencia els habitatges de lloguer dels de propietat, essent els segons de major superfície (amb una superfície mitjana de $88 \mathrm{~m} 2$ ) que els primers $(76,5 \mathrm{~m} 2)$. Ara bé, cal tenir en compte que els habitatges en règim de lloguer són de caràcter més temporal $\mathrm{i}$ majoritàriament responen a les necessitats del moment present, podent-lo canviar amb major facilitat que el de propietat. I la segona diferencia fa referència a l'edat de la persona, amb una superfície lleugerament superior als habitatges més joves $(85,4 \mathrm{~m} 2$ vs $84,5 \mathrm{~m} 2)$, especialment els de propietat, que maximitzen les diferències, amb una superfície mitjana de les llars més joves de $89,8 \mathrm{~m} 2$ i de $85,8 \mathrm{~m} 2$ per a les de més edat. Ara bé, l'ordre s'inverteix quan es tracta d'habitatges de lloguer, amb superfícies més grans per als habitatges joves de més edat (amb $80,3 \mathrm{~m} 2)$ i menors superfícies $(73,2 \mathrm{~m} 2)$ per als més joves.

Ara bé, les superfícies estan molt condicionades pel moment d'adquisició de l'habitatge en règim de propietat, car, en tractar-se de l'edat d'emancipació i no de l'edat actual, no és d'estranyar que els habitatges joves de majors superfícies siguin els de les persones més joves, doncs són les que fa més temps que es van emancipar, quan el preu de l'habitatge no havia ascendit fins als límits amb què ho ha fet els darrers anys ${ }^{14}$. Doncs, la superfície dels habitatges joves segons el règim de tinença i el grup d'edat actual és inferior per als grups més joves, amb una mitjana de 15,6m2 menys que les llars dels joves de més edat ${ }^{15}$.

Finalment, la percepció de comoditat i/o permissibilitat econòmica per al pagament de l'habitatge en funció de l'edat i el règim de tinença conclouen les característiques de l'habitatge i les llars joves vers el procés d'emancipació. Tant pel que fa a la percepció subjectiva com pel que fa a l'esforç econòmic real, en termes de percentatge dels ingressos mensuals nets destinats al pagament de l'habitatge.

\section{Taula 3 Comoditat/permissibilitat en el pagament de l'habitatge} per règim de tinença i grups d'edat en el moment de l'emancipació

\begin{tabular}{lll|ll} 
& \multicolumn{2}{c|}{ Propietat } & \multicolumn{2}{c}{ Lloguer } \\
\cline { 2 - 5 } & Sí & No & Sí & No \\
\hline Edat de primera emancipació & 59 & 45 & 29 & 10 \\
(15-24 anys) & 56,73 & 43,27 & 74,36 & 25,64 \\
\hline Edat d'emancipació estable & 65 & 38 & 26 & 9 \\
(25-34 anys) & 63,11 & 36,89 & 74,29 & 25,71 \\
\hline \multirow{2}{*}{ Total } & 124 & 83 & 55 & 19 \\
& 59,90 & 40,10 & 74,32 & 25,68 \\
\hline
\end{tabular}

Font: dades provinents de l'enquesta. Elaboració pròpia

La taula 3 posa de manifest una major comoditat en el pagament de l'habitatge quan es tracta d'un habitatge en règim de lloguer, el $74,3 \%$ de la mostra que resideix en habitatges de lloguer considera que la quota mensual que paga li resulta còmode; mentre en el cas de la propietat descendeix al 59,9\%. Ara bé, distingint per edats en el cas del lloguer gairebé no hi ha diferència entre ambdós grups d'edat; mentre la propietat suposa una major dificultat en els grups de menys edat, amb un $43,3 \%$ de la mostra que considera que la quota mensual no li resulta còmode $o$ assequible.

\footnotetext{
${ }^{14}$ De les 162 persones joves emancipades d'entre 15 i 24 anys en el moment en què ho van fer, només 24 (el $\left.15 \%\right)$ segueix pertanyent a aquest grup d'edat en el moment actual.

${ }^{15}$ Vegi's annex gràfic 3
} 
Figura 2 Esforç econòmic de les llars joves per al pagament de l'habitatge per règim de tinença.

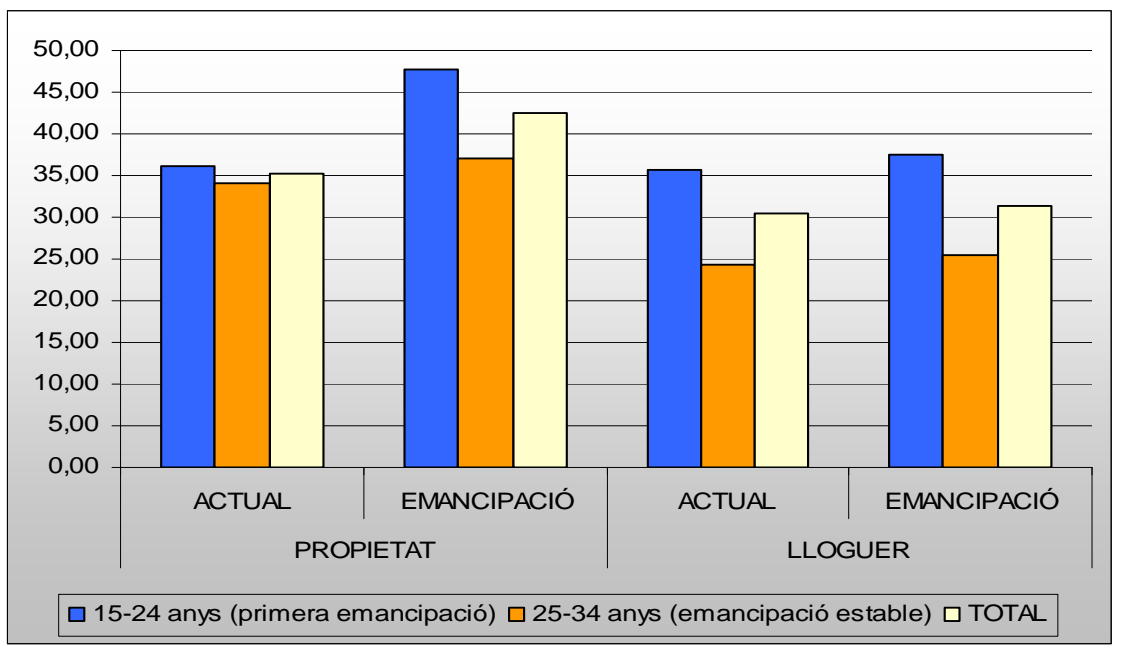

Font: dades provinents de l'enquesta. Elaboració pròpia

Finalment, la figura 2 mostra com, efectivament, l'esforç econòmic que ha de fer una llar per al pagament de l'habitatge és superior quan es tracta d'un habitatge de propietat $(35,2 \%)$ que de lloguer $(30,5 \%)$. Ara bé, també és superior en el moment de l'emancipació que en el moment present $\mathrm{i}$, igualment, en l'etapa d'emancipació primària que en el moment en què s'ha consolidat i estabilitzat (a partir dels 25anys). El major esforç econòmic el realitzen les persones joves del primer grup d'edat quan s'emancipen, especialment si ho fan en règim de propietat $(47,8 \%$, mentre si ho fan en règim de lloguer descendeix al $37,6 \%)$. Ara bé, la reducció d'aquest esforç al moment present és superior en el règim de propietat que en el de lloguer, tot i que aquest segueix sent inferior a l'anterior; fet que es deu a l'increment de preus dels darrers anys que afecten especialment a la mostra emancipada més recentment.

Per tant, la forma d'accés a l'habitatge que afavoreix una màxima comoditat per al pagament del mateix és a través del lloguer, que, a més, proporciona una major flexibilitat amb una major facilitat per canviar-lo per un altre a mida que les necessitats ho requereixin. Doncs, malgrat l'elevat esforç que fan les llars per al pagament d'un habitatge en règim de propietat, un 52,7\% no el considera perdurable, ans al contrari, el canviaria en un futur en què les necessitats com fóra l'ampliació de la família, ho requerissin.

Però, a més, la diferència que amaga l'esforç econòmic expressat a la figura 2 i que mostra la taula 3 amb la percepció subjectiva d'aquest esforç, és el fet que, a part de la quota mensual de la hipoteca, l'habitatge de propietat porta incloses una sèrie de despeses provinents d'impostos, despeses comunitàries,... que a l'esforç econòmic no es comptabilitzen però que sí que hi són presents en la percepció de la comoditat o incomoditat del pagament de l'habitatge; $i$ que, a més, sovint no es tenen en compte a l'hora de prendre la decisió sobre el règim de tinença de l'habitatge de residència. De manera que, la quota mensual que en un primer moment era assumible deixa de ser-ho en sumar-s'hi el conjunt de despeses agregades a la propietat. Així doncs, si bé es tenen en compte les desgravacions fiscals dels habitatges de propietat cal comptabilitzar igualment les despeses agregades a aquesta per valorar el cost real del mateix; així com l'esforç i la capacitat de reposició o d'intercanvi en cas d'haver de canviar d'habitatge.

\section{DETERMINANTS DEL PROCÉS D’EMANCIPACIÓ}


Per tal de completar l'anàlisi s'han cercat les variables més determinants en el procés d'emancipació mitjançant regressions logístiques. En primer lloc, distingint les variables segons es tracti de variables objectives o subjectives (valoracions i opinions personals) s'han realitzat les regressions pertinents per a cada tipus de variables i, en segon Iloc, se n'han realitzat amb totes les variables. Donat que en el primer cas només es consideren unes o altres variables la representativitat de la regressió es redueix, però s'inclouen els principals resultats en ser explicatius del procés d'emancipació i complementar la regressió conjunta.

Per identificar els elements objectius més determinants s'han considerat dues regressions logístiques que es complementen. Ambdues expliquen vora el $70 \%{ }^{16}$ de la mostra amb una probabilitat d'encert del 55\% a partir de tres variables explicatives, ara bé, mentre ambdues regressions coincideixen amb les dues més significatives, l'edat i el nivell d'estudis en el moment de l'emancipació, la tercera és la que complementa ambdues anàlisi: la primera considera com a determinant en tercer lloc el nivell d'ingressos mensuals nets, i la segona el tipus de contracte laboral en el moment de l'emancipació.

Taula 4 Variables a l'equació. Regressió logística amb variables objectives 1.

\begin{tabular}{|ll|l|l|l|l|l|l|}
\hline & B & E.T. & Wald & gl & Sig. & Exp(B) \\
\hline Pas 3(c) & Edat agrupada & 1,843 &, 290 & 40,49 & 1 &, 000 & 6,314 \\
& Nivell d'estudis moment emancipació &,- 341 &, 115 & 8,737 & 1 &, 003 &, 711 \\
& Ingressos mensuals nets &, 254 &, 126 & 4,057 & 1 &, 044 & 1,289 \\
& Constant & $-2,484$ & 1,003 & 6,139 & 1 &, 013 &, 083 \\
\hline
\end{tabular}

a Variable(s) introduïda(s) al Pas 1: EDAT_AGR. (Edat agrupada)

b Variable(s) introduïda(s) al Pas 2: P06A_EM. (Nivell d'estudis moment emancipació)

c Variable(s) introduïda(s) al Pas 3: P36. (Ingressos mensuals nets)

Taula 5 Variables a l'equació. Regressió logística amb variables objectives 2.

\begin{tabular}{|ll|l|l|l|l|l|l|}
\hline & B & E.T. & Wald & gl & Sig. & Exp(B) \\
\hline Pas 3(c) & Edat agrupada & 2,036 &, 276 & 54,46 & 1 &, 000 & 7,664 \\
& Nivell d'estudis moment emancipació &,- 350 &, 113 & 9,521 & 1 &, 002 &, 705 \\
& Contracte moment emancipació &, 521 &, 254 & 4,216 & 1 &, 040 & 1,684 \\
& Constant & $-3,119$ & 1,021 & 9,325 & 1 &, 002 &, 044 \\
\hline
\end{tabular}

a Variable(s) introduïda(s) al Pas 1: EDAT_AGR (Edat agrupada).

b Variable(s) introduïda(s) al Pas 2: P06A_EM. (Nivell d'estudis en el moment emancipació)

c Variable(s) introduïda(s) al Pas 3: P06C_EM (Contracte laboral en el moment emancipació)

A més, el signe de les variables divergeix de la mateixa manera a totes dues anàlisi, mentre la primera i la tercera variable expliquen l'emancipació, la segona explica la no emancipació. És a dir, l'edat i el nivell d'ingressos i/o la relació contractual en el moment de l'emancipació (segons es consideri la primera o la segona regressió logística) són elements determinants en el procés d'emancipació. Per tant, com més edat i més ingressos i/o un contracte laboral més estable en

\footnotetext{
${ }^{16}$ La primera inclou 291 casos en l'anàlisi, el 71\% de la mostra i la segona n'inclou 279, el 68\%.
} 
el moment en què es porta a terme l'emancipació, més probabilitat d'emancipar-se, doncs es tracta de factors que l'afavoreixen. Mentre el nivell d'instrucció en el moment de l'emancipació és un element característic de la mostra no emancipada, és el nivell d'instrucció que esperen i/o desitgen tenir en el moment en que s'emancipin que, com s'ha comentat a l'apartat de característiques de la joventut, és un element sobrevalorat per la mostra no emancipada, amb una expectativa molt superior a llurs coetanis emancipats.

Per tant, aquesta primera aproximació a l'explicació del procés d'emancipació corrobora les hipòtesi plantejades amb anterioritat, en què l'edat i l'ocupació són elements determinants. Però a l'anàlisi realitzat amb anterioritat a partir de les dades estadístiques ${ }^{17}$, que donava com a determinants de l'emancipació l'ocupació i l'estabilitat del contracte laboral, s'hi afegeix el nivell d'ingressos. I, com a factor limitador de l'emancipació, el nivell d'estudis esperat; amb el qual es corrobora la hipòtesi que, en allargar el procés de formació es retarda l'emancipació. Considerant els resultats d'ambdues regressions com a complementaris que, cal tractar a part de les variables subjectives per valorar llur importància, doncs en considerar-les totes juntes passen més desapercebudes degut a la major rellevància d'altres variables.

D'altra banda, els elements subjectius de l'emancipació, a partir de les opinions i valoracions personals, complementen l'anàlisi anterior aportant els elements que no proporciones les estadístiques tradicionals. En aquest cas només s'inclou una regressió logística que per ella mateixa ja és prou significativa; doncs explica el $85 \%{ }^{18}$ de la mostra amb una probabilitat d'encert del 52\%. I les variables subjectives determinants en el procés d'emancipació són, per ordre de significació,: la dificultat per trobar habitatge, acabar els estudis abans d'emancipar-se, la valoració del grau de dificultat en el procés d'emancipació, tenir amics/companys de pis, el control familiar de les companyies i llocs freqüentats, la llibertat a la llar d'origen per portar la parella a casa esporàdicament, tenir accés a un habitatge assequible, consideració respecte l'ajustament de l'oferta d'habitatges a llurs necessitats i l'ajuda de la família.

\begin{tabular}{|c|c|}
\hline EMANCIPACIÓ & NO EMANCIPACIÓ \\
\hline Dificultat en el procés d'emancipació & Dificultat per trobar habitatge \\
\hline Control familiar (companys, llocs freqüentats) & Acabar els estudis abans d'emancipar-se \\
\hline Llibertat a la llar d'origen (portar la parella) & Tenir amics/companys de pis \\
\hline Ajuda de la família & Tenir accés a un habitatge assequible \\
\hline & Ajustament oferta d'habitatges - necessitats \\
\hline
\end{tabular}

Taula 6 Variables a l'equació. Regressió logística amb variables subjectives

\begin{tabular}{|ll|l|l|l|l|l|l|}
\hline & & B & E.T. & Wald & gl & Sig. & Exp(B) \\
\hline Pas & Acabar estudis abans emancipar-se &,- 438 &, 113 & 15,054 & 1 &, 000 &, 645 \\
9(i) & Tenir accés habitatge assequible &,- 346 &, 143 & 5,817 & 1 &, 016 &, 708 \\
& Ajuda de la família &,- 212 &, 106 & 3,952 & 1 &, 047 &, 809 \\
& Tenir companys de pis &,- 416 &, 114 & 13,235 & 1 &, 000 &, 659 \\
& Control familiar companyies, llocs,,$\ldots$ &, 199 &, 060 & 10,969 & 1 &, 001 & 1,220 \\
& Dificultat per trobar habitatge & $-2,690$ &, 472 & 32,444 & 1 &, 000 &, 068 \\
& Oferta hab i ajustament necessitats &,- 956 &, 423 & 5,123 & 1 &, 024 &, 384 \\
& dificultat procés emancipació &, 284 &, 068 & 17,382 & 1 &, 000 & 1,329
\end{tabular}

\footnotetext{
${ }^{17}$ Vegi's l'article emancipación, mercado hipotecario y residencial de la revista ACE. Número 4. Juny 2007

${ }^{18}$ Inclou 349 casos, el 85\% mostra. Però, igual que les regressions objectives explica en major proporció l'emancipació que la no emancipació.
} 
a Variable(s) introduïda(s) al Pas 1: P14. (Dificultat per trobar habitatge)

b Variable(s) introduïda(s) al Pas 2: P05_A. (Acabar els estudis abans d'emancipar-se) ${ }^{19}$

c Variable(s) introduïda(s) al Pas 3: P25. (Grau de dificultat en el procés d'emancipació)

d Variable(s) introduïda(s) al Pas 4: P05_H. (Tenir amics/companys de pis)

e Variable(s) introduïda(s) al Pas 5: P07_E (control familiar respecte companyies, llocs freqüentats) $)^{20}$

f Variable(s) introduïda(s) al Pas 6: P07_H. (Llibertat portar la parella a casa esporàdicament)

$g$ Variable(s) introduïda(s) al Pas 7: P05_D. (Tenir accés a un habitatge assequible)

h Variable(s) introduïda(s) al Pas 8: P17. (Valoració sobre l'oferta d'habitatges i l'ajustament d'aquesta a llurs necessitats)

i Variable(s) introduïda(s) al Pas 9: P05_E. (Ajuda de la família)

Per tant, el fet de considerar el procés d'emancipació com a relativament fàcil o, almenys, més fàcil del que considera la mostra no emancipada, el control de la família d'origen respecte les companyies i els llocs freqüentats tot i la llibertat per portar la parella a casa esporàdicament i requerir menys ajuda de la família per a l'emancipació, són els elements subjectius més determinants; amb una clara incidència de la relació que tenien amb la família i una valoració més positiva i optimista del procés d'emancipació. Mentre la mostra no emancipada té una visió més negativa, amb més traves per portar-la a terme i amb molta recurrència als aspectes relacionats amb l'habitatge: considera que és difícil trobar habitatge, que és important acabar els estudis abans d'emancipar-se (que coincideix amb la regressió logística amb variables objectives), que és important tenir amics o companys de pis i tenir accés a un habitatge assequible i que l'oferta d'habitatges no s'ajusta a les seves necessitats.

Així doncs, els elements més determinants de l'emancipació que fins aquí es desprenen són: l'edat, la relació contractual i el nivell d'ingressos (com a variables objectives) i la relació amb la família i una valoració més positiva i optimista del procés d'emancipació (com a variables subjectives) com a determinants perquè es produeixi l'emancipació. Amb el nivell d'estudis en el moment de l'emancipació (com a variable objectiva) i una valoració negativa i pessimista del procés d'emancipació amb molta rellevància dels aspectes relacionats amb l'habitatge (com a variables subjectives) com a limitadors de l'emancipació.

Ara bé, la regressió logística amb totes les variables (tant objectives com subjectives) mostra els elements més determinants en el procés d'emancipació, incloent-ne de nous a les regressions anteriors i excloent-ne d'altres que passen més desapercebuts i perden significació en afegir-se el conjunt de variables. En aquest cas l'anàlisi explica el $72 \%{ }^{21}$ de la mostra amb una probabilitat d'encert del $70 \%$, per tant és la més fiable de les tres, i amb una major proporció de variables determinants de l'emancipació que de la no emancipació a partir de les següents variables:

\begin{tabular}{|c|c|}
\hline EMANCIPACIÓ & NO EMANCIPACIÓ \\
\hline Edat & Acabar els estudis abans d'emancipar-se \\
\hline Dificultat en el procés d'emancipació & Tenir feina \\
\hline Control familiar (companys, llocs freqüentats) & \\
\hline Ingressos mensuals nets & \\
\hline
\end{tabular}

\footnotetext{
${ }^{19}$ La pregunta 5 consisteix a valorar de l' 1 al 5 el grau en amb què influencia cadascun dels factors en el fet que s'hagi emancipat/s'emancipi en el moment en què ho ha fet/ho farà (on 1 és gens important i 5 molt important)

${ }^{20}$ La pregunta 7 fa referència a la relació amb la família d'origen, consisteix a valorar diferents aspectes de l'1 al 7 (on 1 és gens i 7 molt)

${ }^{21}$ Inclou 295 casos, el $72 \%$ de la mostra.
} 
Tenir parella

Taula 7 Variables a l'equació. Regressió logística amb variables objectives i subjectives

\begin{tabular}{|ll|r|r|r|r|r|r|}
\hline & \multicolumn{1}{|c|}{ B } & \multicolumn{1}{|c}{ E.T. } & \multicolumn{1}{c|}{ Wald } & gl & \multicolumn{1}{c|}{ Sig. } & \multicolumn{1}{c|}{ Exp(B) } \\
\hline Pas & Acabar estudis abans emancipar-se &,- 451 &, 162 & 7,803 & 1 &, 005 &, 637 \\
$7(\mathrm{~g})$ & Tenir feina &,- 531 &, 257 & 4,272 & 1 &, 039 &, 588 \\
& Tenir parella &, 347 &, 151 & 5,257 & 1 &, 022 & 1,415 \\
& Control familiar companyies, llocs,... &, 315 &, 083 & 14,429 & 1 &, 000 & 1,371 \\
& Dificultat en el procés d'emancipació &, 413 &, 100 & 16,987 & 1 &, 000 & 1,511 \\
& Ingressos mensuals nets &, 318 &, 145 & 4,813 & 1 &, 028 & 1,375 \\
& Edat agrupada & 2,102 &, 326 & 41,581 & 1 &, 000 & 8,183 \\
Constant & $-5,980$ & 1,621 & 13,606 & 1 &, 000 &, 003 \\
\hline
\end{tabular}

a Variable(s) introduïda(s) al Pas 1: EDAT_AGR. (Edat agrupada)

b Variable(s) introduïda(s) al Pas 2: P05_A. (Acabar els estudis abans d'emancipar-se ${ }^{22}$

c Variable(s) introduïda(s) al Pas 3: P25. (Grau de dificultat en el procés d'emancipació)

d Variable(s) introduïda(s) al Pas 4: P07_E (Control familiar respecte les companyies, llocs freqüentats... $)^{23}$

e Variable(s) introduïda(s) al Pas 5: P36. (Nivell d'ingressos mensuals nets)

f Variable(s) introduïda(s) al Pas 6: P05_F. (Tenir parella)

g Variable(s) introduïda(s) al Pas 7: P05_B. (Tenir feina)

Per tant, l'edat, el fet de considerar el procés d'emancipació com a relativament fàcil o, almenys, més fàcil del que considera la mostra no emancipada, el control de la família d'origen respecte les companyies i els llocs freqüentats, el nivell d'ingressos i tenir parella són els elements més determinants del procés d'emancipació. L'edat és el principal factor, que, a més, condiciona tots els altres, doncs la molèstia que ocasiona l'excessiu control familiar amb l'edat incrementa, també van lligats a l'edat (en tant que consolidació al món laboral) el nivell d'ingressos i la probabilitat de tenir parella; aquests factors determinen l'emancipació que, alhora es produeix amb més probabilitat a mida que incrementa l'edat, amb una valoració més positiva del procés deguda, en part, a la major estabilitat i les millors condicions.

D'altra banda, com a elements limitadors de l'emancipació, els que més representen la mostra no emancipada, són la consideració respecte la finalització del període de formació i la importància de l'ocupació per emancipar-se. No és que la mostra emancipada no consideri l'ocupació com una variable important, sinó que la mostra no emancipada, degut a la visió pessimista i de dificultat del procés d'emancipació, la considera més important.

Així doncs, són rellevants l'edat, la situació familiar i el nivell d'ingressos, així com el fet de tenir parella, el qual suposa una reducció de la càrrega individual del cost de l'habitatge i les despeses domiciliàries i familiars a més de ser la llar nuclear simple el model de llar jove més significativa, així com la valoració del procés amb més optimisme i facilitat, no tant com a foment de l'emancipació com a no limitador d'aquesta. A més, indirectament, s'inclouen les variables del nivell d'instrucció i de taxa d'ocupació, en representar la mostra no emancipada, tot corroborant les hipòtesis anteriors; igualment, la inclusió de la parella com a variable determinant del procés d'emancipació, porta implícits la repartició de la càrrega econòmica i personal de l'emancipació així com la variable subjectiva que apareixia a l'anàlisi anterior,

\footnotetext{
${ }^{22}$ La pregunta 5 consisteix a valorar de l'1 al 5 el grau en amb què influencia cadascun dels factors en el fet que s'hagi emancipat/s'emancipi en el moment en què ho ha fet/ho farà (on 1 és gens important i 5 molt important)

${ }^{23}$ La pregunta 7 fa referència a la relació amb la família d'origen, consisteix a valorar diferents aspectes de l'1 al 7 (on 1 és gens i 7 molt)
} 
sobre la importància de tenir amics o companys de pis, també amb la repercussió del repartiment de càrregues econòmiques que comporta. Afegint-se variables referents a la relació la familiar a la llar d'origen i les llibertats personals i la valoració subjectiva del procés d'emancipació.

\section{CONCLUSIONS I PROPOSTES}

En un context social, econòmic, polític i residencial com l'actual, en què el procés de formació s'ha allargat amb un retard de l'accés i, sobretot, la consolidació al mercat laboral, retardant igualment l'emancipació domiciliar. Emancipació residencial, lligada al cicle vital i a la formació de la llar que, en la majoria dels casos comporta la creació d'una nova llar nuclear; i alhora condicionada per un mercat residencial rígid, amb un marge molt estricte i restringit per règims de tinença i gestió distints a la propietat privada, i amb un parc d'habitatge públic i protegit insuficient.

En aquest context, no és d'estranyar que la mostra no emancipada, i potencial demanda d'habitatge, tingui una percepció pessimista de l'emancipació doncs, a més, té una situació més precària. Però, l'expectativa de millora per al moment en què s'emancipin és molt optimista, inclús per sobre de la realitat de llurs coetanis emancipats tant en el moment actual com en el moment de l'emancipació. Per tant, es tracta d'una barrera en termes de seguretat, bàsicament laboral, econòmica i de nivell d'instrucció; sense la qual no es veuen capacitats per afrontar la situació actual del mercat residencial i el cost d'accés a l'habitatge. Però, el procés d'emancipació, que en un principi requereix d'un esforç econòmic i personal elevat, amb el temps es consolida, millorant la percepció d'aquest. Ara que, l'expectativa tant optimista de la mostra no emancipada posa en perill l'acompliment d'aquesta millora.

Pel que fa a la consolidació de l'emancipació es produeixen dues situacions: la primera és la de les llars més joves, que, en trobar-se en un moment del procés més precari, sovint subjecte a situacions i processos canviants relacionats amb el mercat laboral, formen llars més variades amb estructures i tipologies menys tradicionals. El qual es correspon amb una major proporció d'habitatges de lloguer que de propietat, doncs la facilitat per canviar d'habitatge és superior a la del règim de propietat, tornant-se per tant més flexibles. La segona situació correspon al grup de més edat, amb una emancipació més estable, sovint lligada al cicle vital i la formació de la llar familiar i que resideix en major proporció en llars nuclears simples i en habitatges de propietat; tot i que la resta de tipologies de llars i de règims de propietat hi són presents en major proporció que a les llars adultes.

La forma d'accés a l'habitatge que afavoreix una màxima comoditat i/o permissivitat per al pagament del mateix és a través del lloguer; però, a més, malgrat l'elevat esforç que fan les llars per al pagament d'un habitatge en règim de propietat, la majoria no el considera perdurable, ans al contrari, el canviaria en un futur en què les necessitats com fóra l'ampliació de la família, ho requerissin. Es produeix així una confrontació entre la capacitat adquisitiva, les necessitats residencials presents i futures i la sobreestimació de la propietat com a bé d'inversió, oblidant el valor d'ús de l'habitatge.

Finalment, per tal de pensar en una política pública que faciliti el procés d'emancipació i l'accessibilitat a l'habitatge cal tenir en compte els elements més determinants en el procés d'emancipació, a saber: l'edat, que porta implícit l'estabilitat laboral, econòmica i personal, la situació familiar en quant a llibertats i control, el nivell d'ingressos i el fet de tenir parella, el qual suposa una reducció de la càrrega individual del cost de l'habitatge i les despeses domiciliàries i familiars, a més de ser la llar nuclear simple el model de llar jove més significativa. En darrer lloc la valoració del procés amb més optimisme i facilitat, no tant com a foment de l'emancipació 
com a no limitador d'aquesta. Indirectament, i com a factors limitadors de l'emancipació s'inclou el nivell d'instrucció i de taxa d'ocupació.

Les diferents polítiques que cal portar a terme per solucionar la problemàtica ja no només de l'emancipació, sinó de l'estabilització d'aquesta i la millora en l'accessibilitat a un habitatge en condicions dignes, tot flexibilitzant i diversificant el mercat immobiliari, són d'ampli abast i no només beneficien al col-lectiu jove, sinó que serveixen per al conjunt de la societat. Per tant, cal distingir entre les diferents polítiques i llurs objectius:

Per tal d'eliminar o, si més no, reduir els factors limitadors de l'emancipació és necessari actuar, d'una banda, en el nivell d'instrucció i el mercat laboral, i de l'altra, en el mercat residencial, que alhora són les principals diferències entre la població emancipada i la que no ho està. En primer lloc cal portar a terme polítiques d'orientació, ocupació i formació laboral, estenent-les a l'àmbit acadèmic, creant una vertadera orientació en l'àmbit acadèmic que tingui continuïtat al laboral, amb borses ocupacionals accessibles i d'abast supramunicipal, juntament amb l'afavoriment de la contractació estable i la flexibilització horària. Tot plegat afavoriria una major integració de l'àmbit acadèmic amb el laboral, afavorint una mobilitat i flexibilitat laboral que, a partir de la flexibilitat horària permet la continuïtat i ampliació del nivell d'instrucció; la conjunció dels quals és l'element més limitador de l'emancipació.

En segon lloc, cal actuar en el mercat immobiliari tant pel que fa a l'oferta d'habitatges com als règims de tinença $\mathrm{i}$ formes gestió, tot aplicant les noves legislacions i promovent una major flexibilitat:

D'acord al principi de desenvolupament urbà sostenible cal, abans de res, mobilitzar el parc d'habitatges desocupat, i no només d'habitatges, de locals, fàbriques i indústries en desús susceptibles de ser rehabilitades i reutilitzades. Bé com a habitatges, bé com a equipaments públics i socials (centres cívics, casals, tallers ocupacionals, tallers de formació,...) ja sigui de caràcter temporal (a partir de la cessió del dret de superfície o del lloguer) o indefinit (a través de la venda), mitjançant una gestió pública, privada o compartida. Fomentar la rehabilitació d'habitatges existents a partir de la implementació dels ajuts públics per a la rehabilitació. I crear-ne de nous als nuclis urbans (i no només a la perifèria) aprofitant els locals i fàbriques que han quedat en desús i que es troben als nuclis urbans, tot mantenint alhora el patrimoni històric.

Pel que fa a la gestió $i$ al règim de tinença cal, d'una banda fomentar els règims de tinença i la gestió públics, intermitjos (públic-privat) i a partir de cooperatives. Incrementant el control dels preus i fomentant noves formes de promoció i gestió de l'habitatge a partir de: cessions del dret de superfície, cooperatives d'habitatge, cooperatives d'usuaris d'habitatge, mediació per al lloguer, creació d'un parc públic d'habitatge,... Així com afavorir la utilització d'espais efímers amb regulacions i activitats flexibles d'acord a les necessitats de la població.

Tot plegat flexibilitzant el mercat immobiliari, des del punt de vista tipològic, estructural, fiscal, gestor i tinent, creant diferents ofertes d'habitatge alternatives a la tradicional i gestionades per diferents entitats, amb un vertader control de preus dels habitatges públics (a partir del dret de tempteig i retracte) que, un cop incrementat el parc i diversificat el mercat residencial, resulti un vertader limitador $i$ controlador del preu de l'habitatge. Fomentant les mesures menys restrictives, amb lloguers tous per facilitar l'accessibilitat al mercat de l'habitatge a les persones més joves, i promovent mesures que diversifiquin l'actual mercat residencial de propietat com a alternatives a aquesta, tornat a l'habitatge llur valor d'ús per sobre el valor de canvi, i promovent el lloguer amb opció de compra per a aquelles persones amb més dificultats que, tot i l'àmplia oferta d'habitatges, segueix desitjant-ne un de propietat. 
Ara bé, aquestes mesures, han d'afavorir la cohesió social i l'accessibilitat al conjunt de la població, amb la integració d'aquestes i d'altres alternatives en el teixit urbà i, quan es tracti de zones de nova construcció, fomentant igualment la cohesió social i la integració de la diversitat tipològica tant a nivell estructural com de gestió en la nova trama urbana. A més, cal complementar-les amb una millora fiscal de l'habitatge de lloguer i la consideració dels habitatges gestionats per cooperatives d'usuaris; facilitant-ne la gestió i l'ús dels mateixos. I a àmbit local cal complementar aquestes actuacions amb una vertadera gestió local i de cooperació supramunicipal, creant borses de lloguer joves d'habitatges públics, privats, en cooperativa,... Doncs sovint, a les ciutats mitjanes i petites la gestió local és complexa i requereix de la cooperació intermunicipal en benefici de la ciutadania.

Aquestes mesures facilitaran l'accessibilitat al mercat laboral i residencial promovent no només un mercat residencial més ampli i diversificat, a més, servirà com a controlador i limitador real del mercat residencial actual i de llurs preus en favor del valor d'ús. Diversificació que alhora, comportarà una major facilitat el procés d'emancipació, tant en la percepció subjectiva com en termes reals d'elasticitat en l'oferta i la demanda i amb l'acompliment d'aquesta màxima en què una major oferta més diversificada i competent comportarà una reducció del preu de l'habitatge. 


\section{BIBLIOGRAFÍA}

Bosch, J.; Gibarja, O. (2003). L'Habitatge a Catalunya en l'àmbit local: diagnosi, propostes $i$ solucions a un problema creixent Barcelona, Fundació Carles Pi i Sunyer d'Estudis Autonòmics i Locals.

Casals, J; Garcia, M.; Merino, R.; Quesada, M. (2004) Enquesta als joves de Catalunya 2002 col.lecció estudis 13, Barcelona, Secretaria General de la Joventut.

Clavell, D. (2003) Instruments urbanístics per a una política de sòl i habitatge a Catalunya Qüestions d'habitatge 11. Barcelona Patronat Municipal de l'Habitatge de Barcelona. Ajuntament de Barcelona.

Clavell, D.; Trilla C. (2004) Propostes alternatives de promoció per a una nova orientació de l'oferta d'habitatge protegit de la societat urbanística metropolitana de rehabilitació i gestió, S.A. REGESA Qüestions d'habitatge 12. Barcelona Patronat Municipal de l'Habitatge de Barcelona. Ajuntament de Barcelona.

Cortés, L (2002) Ciudad, vivienda y ciudadanía. Modelos de desarrollo urbano / modelos de ciudad. La ciudad como un organismo sujeto a procesos Constants de transformación. 25 de Junio de 2002

De la Cruz, A (2007): La Llei 8/2007, de sòl: principals novetats. L'estatut de la propietat urbana. Jornada tècnica La Llei estatal de sòl: nou marc jurídic per a l'urbanisme municipal. Oficina Tècnica de Cooperació de la Diputació de Barcelona.

El Mundo. Economía. 30 de Marzo de 2004. El sector de la construcción aportó un 17,7\% al PIB en 2003.

Garcia, A (2007): emancipación, mercado hipotecario y residencial. Revista ACE. Número 4 juny 2007.

Garcia, P.; Garcia, A.; Fullaondo, A. (2005) Problemàtica de l'habitatge dels joves a Catalunya. Barcelona Centre de Política del Sòl i Valoracions de la UPC.

Garcia, P.; Renau, A. (1993) L'emigració de Barcelona: causes i característiques. El mercat de l'habitatge com a factor incentivador de l'emigració. Barcelona Centre de Política del Sòl i Valoracions de la UPC.

Generalitat de Catalunya (2004) Informe sobre el sector de l'habitatge a Catalunya 2004. Generalitat de Catalunya. Departament de Medi Ambient i Habitatge. Direcció General d'Habitatge.

Mancomunitat de Municipis de l'Àrea Metropolitana de Barcelona; Iglesias, A.; Vendrell, J. (2003) Habitatge protegit metropolità: 1995-2003 Barcelona, Mancomunitat de Municipis de l'Àrea Metropolitana de Barcelona.

Miret, P. (2004) Emancipació domiciliària, laboral i familiar dels joves de Catalunya Col-lecció aportacions 25, Barcelona, Secretaria General de la Joventut.

Observatori Català de la Joventut (2005): Informe sobre la joventut al 2005. Col-lecció Estudis, n¹7. Observatori Català de la Joventut. Secretaria General de Joventut

Trilla, C.; Institut DEP (2000) Els joves catalans i l'habitatge colllecció estudis 3, Barcelona, Secretaria General de la Joventut.

Trilla, C.; DEP Consultoria Estratègica (2004) Els joves catalans i l'habitatge 1999-2003 col·lecció estudis 12, Barcelona, Secretaria General de la Joventut. 


\section{ANNEX}

Quadre 1. Quadre resum de les característiques de la joventut emancipada i no emancipada en el moment present i en el moment de l'emancipació ${ }^{24}$.

\begin{tabular}{|c|c|c|c|c|}
\hline & \multicolumn{2}{|c|}{ MOSTRA EMANCIPADA } & \multicolumn{2}{|c|}{ MOSTRA NO EMANCIPADA } \\
\hline & ACTUALMENT & EMANCIPACIÓ & ACTUALMENT & EMANCIPACIÓ \\
\hline \multirow{2}{*}{$\begin{array}{c}\text { NIVELL } \\
\text { D'INSTRUCCIÓ }\end{array}$} & + estudis & + estudis & - estudis & + estudis \\
\hline & \multicolumn{2}{|c|}{$\begin{array}{c}\text { Incrementa respecte el moment } \\
\text { d'emancipació }\end{array}$} & \multicolumn{2}{|c|}{$\begin{array}{l}\text { Esperen que incrementi més del } \\
\text { que ho ha fet l'emancipada }\end{array}$} \\
\hline \multirow{3}{*}{$\begin{array}{l}\text { SITUACIÓ LABORAL } \\
\text { CONTRACTUAL }\end{array}$} & + ocupació & - ocupació & - ocupació & + ocupació \\
\hline & + estabilitat & + estabilitat & - estabilitat & + estabilitat \\
\hline & + categoria & - categoria & - categoria & + categoria \\
\hline $\begin{array}{l}\text { INGRESSOS } \\
\text { MITJANS (MES) }\end{array}$ & $\begin{array}{c}1.153 € \\
2.267 € \text { (llar) }\end{array}$ & $\begin{array}{c}967 € \\
1954 €(\text { Ilar) }\end{array}$ & $682 €$ & - \\
\hline $\begin{array}{c}\text { LLOGUER/HIPOTECA } \\
\text { MENSUAL }\end{array}$ & $\begin{array}{c}679 € \\
(699,6 €-677 €)\end{array}$ & $\begin{array}{c}556 € \\
(607 €-552 €)\end{array}$ & - & $\begin{array}{c}860,5 € \\
(843 €-912,5 €)\end{array}$ \\
\hline $\begin{array}{c}\text { ESFORÇ ECONÒMIC } \\
\text { (LLAR) }\end{array}$ & $\begin{array}{c}34 \% \\
(39,5 \%-34 \%)\end{array}$ & $\begin{array}{c}39,6 \% \\
(37 \%-40 \%)\end{array}$ & - & - \\
\hline
\end{tabular}

Font: dades provinents de l'enquesta. Elaboració pròpia

Gràfic 3 Superfícies dels habitatges joves segons règim de tinença i grup d'edat actual

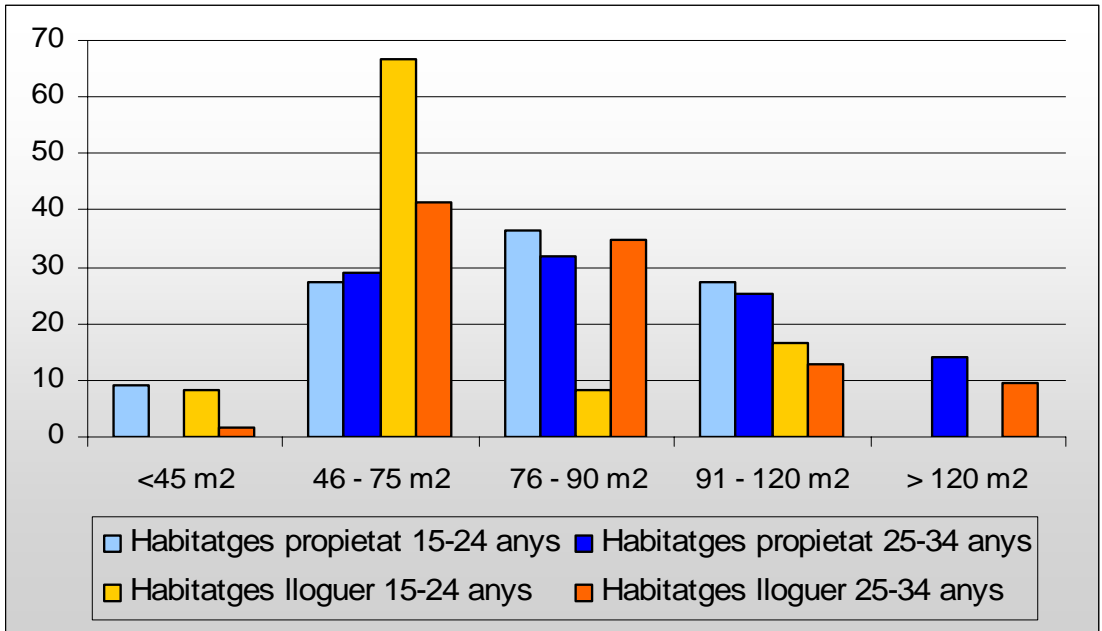

Font: dades provinents de l'enquesta. Elaboració pròpia

\footnotetext{
${ }^{24}$ El quadre compara les característiques de la mostra emancipada amb les de la no emancipada i la situació actual amb la del moment de l'emancipació que, en el cas de la mostra emancipada és anterior a l'actual i en el cas de la no emancipada és la situació esperada, amb unes expectatives de millora gairebé sempre superiors a les de la realitat de la mostra emancipada.
} 